\title{
Longer hospital stay is associated with higher rates of tuberculosis-related morbidity and mortality within 12 months after discharge in a referral hospital in Sub-Saharan Africa
}

\author{
Nicola M Zetola1, ${ }^{1,3^{*}}$, Nenad Macesic ${ }^{4}$, Chawangwa Modongo ${ }^{1,3}$, Sanghuk Shin ${ }^{5}$, Ronald Ncube ${ }^{6}$
} and Ronald G Collman ${ }^{7}$

\begin{abstract}
Background: Nosocomial transmission of pulmonary tuberculosis (PTB) is a problem in resource-limited settings. However, the degree of TB exposure and the intermediate- and long-term morbidity and mortality of hospital-associated $T B$ is unclear. In this study we determined: 1) the nature, patterns and intensity of TB exposure occurring in the context of current TB cohorting practices in medical centre with a high prevalence of TB and HIV; 2) the one-year TB incidence after discharge; and 3) one-year TB-related mortality after hospital discharge.

Methods: Factors leading to nosocomial TB exposure were collected daily over a 3-month period. Patients were followed for 1-year after discharge. TB incidence and mortality were calculated and logistic regression was used to determine the factors associated with TB incidence and mortality during follow up.

Results: 1,094 patients were admitted to the medical wards between May 01 and July 31, 2010. HIV was confirmed in 690/1,094 (63.1\%) of them. A total of 215/1,094 (19.7\%) patients were diagnosed with PTB and 178/1,094 (16.3\%) patients died during the course of their hospitalization; 12/178 (6.7\%) patients died from TB-related complications. Eventually, 916 (83.7\%) patients were discharged and followed for one year after it. Of these, 51 (5.6\%) were diagnosed with PTB during the year of follow up (annual TB rate of 3,712 cases per 100,000 person per year). Overall, $57 / 916$ (6.2\%) patients died during the follow up period, of whom 26/57 (45.6\%) died from confirmed TB. One-year TB incidence rate and TB-associated mortality were associated with the number of days that the patient remained hospitalized, the number of days spent in the cohorting bay (regardless of whether the patient was eventually diagnosed with TB or not), and the number and proximity to TB index cases. There was no difference in the performance of each of these 3 measurements of nosocomial TB exposure for the prediction of one-year TB incidence.
\end{abstract}

Conclusion: Substantial TB exposure, particularly among HIV-infected patients, occurs in nosocomial settings despite implementation of cohorting measures. Nosocomial TB exposure is strongly associated with one-year TB incidence and TB-related mortality. Further studies are needed to identify strategies to reduce such exposure among susceptible patients.

Keywords: Tuberculosis, Transmission, Nosocomial, Infection control, HIV, Morbidity, Mortality

\footnotetext{
* Correspondence: nzetola@hotmail.com

'Division of Infectious Disease, University of Pennsylvania, Philadelphia,

Pennsylvania, USA

${ }^{2}$ University of Botswana Medical School, University of Botswana, Gaborone,

Botswana

Full list of author information is available at the end of the article
} 


\section{Background}

Tuberculosis remains one of the major public health problems worldwide $[1,2]$. This high burden of disease together with the increasing prevalence of resistant strains highlights the need to maximize infection control measures in settings in which TB transmission is likely occurring $[3,4]$. Nosocomial outbreaks of TB have been well documented [5-9]. In areas were HIV and TB are highly prevalent, health care settings select for HIV patients with advanced disease, usually admitted for the treatment of infectious complications, who may be highly susceptible to TB infection and disease, as well as TB patients with complicated disease, often highly infectious, that have failed outpatient treatment (e.g. severe cavitary disease, extensive, multilobar disease and drug-resistant TB). Therefore, nosocomial acquisition of TB among HIV-infected and other susceptible patients is believed to be a major source of morbidity and mortality and may significantly contribute to the spread of disease in the community [5].

One widely used strategy, advocated as an alternative to individual isolation, is the cohorting of patients admitted with confirmed or suspected TB ("TB bays") [10]. However, despite widespread use worldwide, the impact of this approach on TB exposure, the intensity of the exposure or, most importantly, transmission in settings with high prevalence of HIV and TB remains unclear [3,4,11]. A major determinant of the effectiveness of cohorting is the performance of the triage approach on admission and the recognition of suspect cases during the hospitalization period. In endemic settings several factors make the situation particularly complicated [5]. First, clinical triage, the most widely used approach for the triage of patients with suspicion for TB worldwide, has poor sensitivity and specificity in identifying patients with TB [12]. Recently, new diagnostic tools with rapid turn-around and greater sensitivity and specificity that may allow appropriate triage of such patients to cohorting wards have become available (e.g. GeneXpert MTB/RIF, Cepheid Inc.) [13-16]. However, these diagnostic tools are not yet widely available in resource-limited settings. Further, even if these new diagnostic tools allow a perfect sensitivity and specificity for the triage of patients with active $\mathrm{TB}$ to the appropriate "TB bay", cohorting these patients (who have already demonstrated themselves as predisposed to develop active TB) together with multiple highly infectious patients may even lead them to acquire infections with multiple TB strains.

Determining TB-related outcomes and the factors associated with them among patients following discharge from settings of potential nosocomial transmission is crucial to better understand the potential impact of nosocomial TB in epidemics, and to inform patients, healthcare workers and policy makers [17-23]. In addition, little is known regarding outcomes of hospitalized TB patients after discharge [10]. TB-infected patients admitted to the hospital tend to have more serious forms of the disease. Thus, determination of the rates and outcomes of TB recurrence or relapse in the community (after patient's discharge) among those who required hospitalization for TB also carries great clinical and public health importance.

Short-term outcomes, such as inpatient mortality and acute functional decline following hospitalisation, have been extensively studied and are well established for a number of medical illnesses (including TB) in both developed and developing country settings. However, few data are available on the intermediate- to long-term TB-related outcomes of patients admitted to the medical wards, especially in developing country settings where documentation and follow-up are problematic [10,24-31]. In this study we determined: 1) the nature, patterns and intensity of TB exposure occurring in the context of current TB cohorting practices in a major urban medical centre with a high prevalence of both TB and HIV; 2) the incidence of TB within the first year after discharge; and 3) the mortality associated with those one-year incident TB cases. Additionally, we determined comprehensive all-cause mortality for all patients admitted to the medical ward, including mortality during the patient's inpatient stay and in the first year after discharge.

\section{Methods}

\section{Settings}

All patients admitted to the medical wards between May 01 and July 31, 2010 at a large tertiary referral hospital in Botswana, were enrolled in this observational cohort. With a base population of approximately 350,000 persons, this hospital serves as the main referral centre for the Southern region of the country [32]. Wards are "open" (Figure 1) and divided according to the sex of the patients.

\section{The medical wards}

This study was conducted at the male and female medical wards which are, by far, the busiest wards in the hospital. At these wards, an average of 400 patients are cared for on a monthly bases (approximately 200 pawith a maximum capacity of 10 patients each (Figure 1 ). Four bays are used for general medical non-TB admissions, while the fifth one is used for the cohorting of patients with suspected or confirmed active pulmonary TB (Figure 1).

\section{Infection control measures in place}

Our hospital follows the guidelines set out in the national TB exposure control guidelines [33]. The TB infection control guidelines are based on the World Health Organization (WHO) recommendations and are based on 


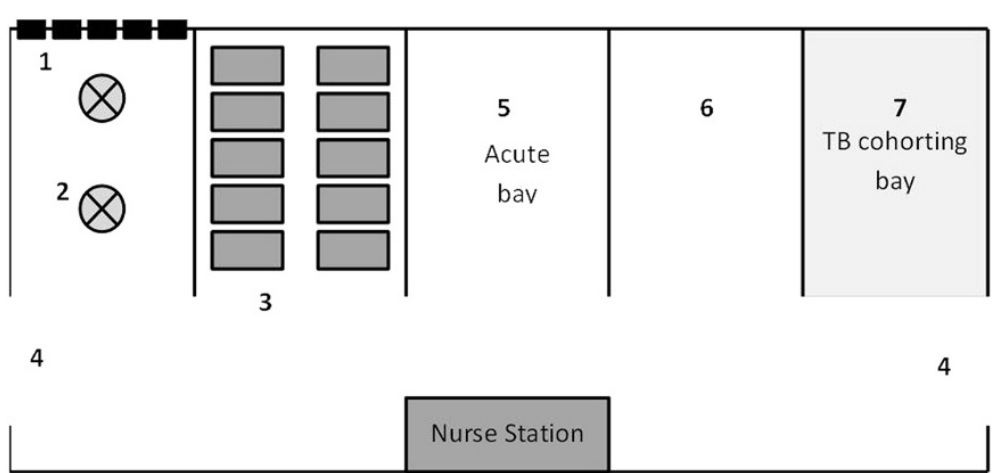

Figure 1 Shows the schematic distribution of the bays and the tuberculosis cohorting bay within the medical ward. Position and number of windows, fans and doors are represented as well. Each ward (male and female) is divided in 5, 10-bed bays (6). (1) Each bay has 5 windows and (2) 2 ceiling fans. (3) Beds are organized in two lines of 5 beds each, located on in front of the other. (4) Double doors are located at each extreme of the ward. (5) Traditionally, sickest patients are located in the bay in front of the nurse station. (7) The most distant bay, located next to the main back door is used as the TB cohorting bay.

a three-level hierarchy of control measures (refer to Additional file 1) [10].

\section{Administrative measures}

Administrative measures include triaging and cohorting of patients suspected to have TB, intensified TB case finding among patients with symptoms and risk factors for TB, early initiation of antituberculous treatment (ATT), and early discharge of patients infected with TB among others.

\section{Use of respiratory protective equipment}

N95 masks required and are used virtually by all health practitioners during direct contact with patients in the TB cohorting ward. Surgical masks are provided to the all patients with diagnosis or suspicion for $\mathrm{TB}$ and their use at all times is encouraged.

\section{Data collection}

Data were collected on standardized forms on a daily basis. Every day, nurses reassess the patients' diagnosis and clinical status as well of cubicle occupancy and staffing and patients relocated accordingly. As most of such patient relocation occurs during the morning nursing shift, all data were consistently collected at the same time of the morning and evening, after the patient relocation was finalized. The number of patients per $\mathrm{cu}-$ bicle, their position, environmental factors was collected at this time. More specifically, the following variables were collected from the medical records:

\section{Demographics and infectiousness of the source/index case} Basic demographics, reason from admission, working diagnosis, admission date, history of TB prior to the current episode (yes/no), history of prior ATT (yes/no and dates). For patients under evaluation for TB, information on the direct observed therapy site and sputum collection was recorded. Whether the patient was suspected to have TB was recorded as not suspected or suspected. Patients with known TB on admission who were on ATT were also considered susceptible for reinfection, relapse or recurrence. All their information was recorded as well. The diagnosis of $\mathrm{TB}$ at discharge was assessed and categorized as no TB, suspected TB or confirmed TB. Patients were considered to have confirmed TB at discharge if they had at least one sputum smear positive for acid-fast bacilli (AFB) obtained during their hospitalization. AFB status and ATT status of patient was carefully recorded. In addition, we followed the location of each patient in the ward (twice a day) and his/her proximity to patients with known PTB.

\section{ATT initiation during hospitalization was noted}

Patients with suspected pulmonary TB (PTB) at the time of discharge were followed at their referral clinics to verify whether the diagnosis of TB was confirmed. Patients with positive AFB smears or cultures were considered as confirmed PTB. Patients that failed to improve with standard pneumonia treatment but that improved on ATT were considered to have clinically confirmed PTB.

\section{Identification of missed diagnosis}

In addition, our study database was matched with the one from the National TB Reference Laboratory to identify missed diagnosis of PTB during the hospitalization period. These missed diagnosis were defined as cases in which PTB was not suspected on admission or discharge or cases in which PTB was suspected on admission but not on discharge but it was confirmed within 3 months after discharge (by self-referral of the patient to a TB clinic). 


\section{Severity of pulmonary disease}

All patients with suspicion or confirmed PTB had a chest $\mathrm{X}$ ray. All $\mathrm{X}$ rays were read by a radiologist and an pulmonologist and an infectious diseases specialist; all with extensive clinical experience in the management of TB patients. Each X ray was divided horizontally by eye into 3 equal zones per lung field. The extent of disease was be determined by the number of zones containing lesions in the lung parenchyma (mild for one zone, moderate for two zones and severe for 3 zones).

\section{Quantification of TB exposure}

To determine how best to assess exposure to infectious PTB patients that may predict the development of active TB during the follow-up period after discharge; we developed a semi-quantitative index of overall TB exposure, and compared the performance of three measurements.

The total number of days admitted to the medical ward.

The total number of days admitted to the hospital divided in: a) days spent at the cohorting bay; versus, b) days spent at the general medical bay.

The third measurement attempted to quantify intensity of exposure by considering the number of adjacent TB patients and the number of non-adjacent TB cases in each bay, every day. To calculate the daily exposure index per participant per day, adjacent cases were given twice the weight of non-adjacent ones. For example, if a participant had 2 adjacent TB cases and one nonadjacent TB patient in his/her bay, the "exposure index" for that day would be calculated as: $2 \times 2+1=5$.

\section{The immune status of the patients at risk}

HIV status and CD4 cell counts were recorded on all patients with new and old HIV diagnosis. History of anti-retroviral therapy (ART) was collected on patients known to be HIV infected at the time of admission. As per routine practice, patients with history of negative or unknown HIV status were re-tested on admission.

\section{Follow up}

Every 3 months for a total of 12 months, data from each enrolled patient were extracted from paper medical records and electronic databases at the hospital, TB clinics, Botswana National Tuberculosis Program, the Botswana National Tuberculosis Reference Laboratory, HIV clinics, and the Botswana National HIV Program. Additionally, the National Death Registry was searched for details about patient mortality, date of death, and hospital readmissions. Data abstraction was focused on the identification of new episodes of $\mathrm{TB}$, episodes of $\mathrm{TB}$ recurrence or relapse, overall mortality and TB-associated mortality. Patients unable to be contacted by any of the above methods were considered 'lost-to-follow-up'. For this analysis, 'untraceable' patients were considered to be alive since their names could not be found in the National Death Registry. Due to the observational nature of the design, patients were never contacted during the entire duration of the study.

\section{Definitions and outcomes}

Given the different rates of progression to active PTB after the exposure of HIV-infected and HIV-uninfected patients, all analyses were performed separately by HIV infection status. Tuberculin conversion was not used as an outcome given the extremely high rates of positivity in our population and the almost universal exposure to TB among adults in our setting. Thus, our main outcomes were TB incidence, all-cause mortality and TB-associated mortality during the follow-up period. We used the World Health Organization (WHO) recommendation to define our TB cases [33,34]: a) Case of TB: A patient in whom TB was confirmed by bacteriology or diagnosed by a clinician. b) Definite case: A patient with positive culture for Mtb or a patient with two sputum smears positive for acid-fast bacilli (AFB+).c) Pulmonary case: A patient with tuberculosis disease involving the lung parenchyma. d) Smear-positive pulmonary case: A patient with one or more initial sputum smear examinations (direct smear microscopy) AFB+; or one sputum examination $\mathrm{AFB}+$ and radiographic abnormalities consistent with active pulmonary tuberculosis as determined by a clinician. e) Smear-negative pulmonary case: A patient with pulmonary tuberculosis not meeting the above criteria for smear-positive disease. Diagnostic criteria included: at least two sputum smear examinations negative for AFB; and radiographic abnormalities consistent with active pulmonary tuberculosis; and a decision by a clinician to treat with a full course of ATT; or positive culture but negative AFB sputum examinations. f) Extrapulmonary case: A patient with tuberculosis of organs other than the lungs (e.g. pleura, lymph nodes, abdomen, genitourinary tract, skin, joints and bones, meninges). Diagnosis was based on one culture-positive specimen, or histological or strong clinical evidence consistent with active extrapulmonary disease, followed by a decision by a clinician to treat with a full course of ATT. A patient in whom both pulmonary and extrapulmonary TB was classified as a pulmonary case. $g$ ) New case: A patient who never had treatment for tuberculosis. h) Re-treatment case: A patient previously treated for $\mathrm{TB}$, who started on a retreatment regimen after previous treatment had failed, who returned to treatment having previously defaulted, or who was previously declared cured or treatment completed and was diagnosed with bacteriologically positive TB (relapse).

\section{Statistical analyses}

Descriptive statistics were determined by standard methods. Groups were compared using Fisher's exact or 
Wilcoxon-rank-sum tests as appropriate. Odds ratios were calculated for all factors potentially associated with a final diagnosis of PTB. We controlled for possible confounding or effect-modifying factors by using logistic regression. We determined potential confounders a priori based on estimation of their significance as epidemiologic factors during the preliminary crude analysis (significant at $p \leq 0.05)$ and biological plausibility. Potential confounders included age, sex and prior TB history. For analyses restricted to those with HIV, we also evaluated the CD4 count and use of ART at baseline as potential confounders. Factors indicating severity of disease included semi-quantitative bacillary load (by AFB microscopy: scanty, $1+, 2+$ and $3+$ ) and chest $\mathrm{X}$ ray results. Potential confounders were considered actual confounders if their inclusion in the multivariable model changed the unadjusted odds ratio (OR) by $10 \%$ or more. In addition, given that our main measures of TB exposure were highly collinear, different models were built for each of those variables. Finally, in an attempt to distinguish patients with the highest probability of having a relapse of their prior TB disease from those who develop active disease due to a nosocomial exposure, we performed separate analyses for the total population and the population of patients who were not diagnosed with TB during their hospital admission. Two-sided $p$-value $<0.05$ was considered statistically significant. We used STATA/IC version 13.0 (StataCorp Inc, College Station, Texas) for the analyses.

\section{Ethics and human subject protection}

The Human Research Committee of the Government of Botswana and the hospital's Ethics Committee approved this study. The need for informed consent from the participant was waived by both Research Ethic Review Committees.

\section{Results}

\section{Before admission to the medical ward}

1,283 patients were scheduled for admission to the medical ward. However, 189 (6.8\%) of them died at the Emergency Department before they could be transferred to the wards. $34(18 \%)$ of these 189 patients had the working diagnosis of pneumonia. TB was retrospectively confirmed through positive AFBs or culture in $4(12 \%)$ and remained as the most probable ethologic agent on 16 (47\%) of those 34 cases of pneumonia (Additional file 2).

\section{During admission to the medical ward}

1094 patients were admitted to the medical wards during the study period. Demographic, clinical and radiographic characteristics of these patients are shown in Tables 1 and 2. Additional file 2 shows the distribution of patients according to the place of admission (cohorted vs. not cohorted) and diagnosis of PTB. Of the admitted patients, 131 (12\%) spent their entire hospital stay at the TB cohorting bay and an additional 80 (7.3\%) spent part of their stay in the TB cohorting bay (Additional file 2). The mean number of days of hospitalization was 7.8 (standard deviation [SD] 6.6) for the entire population, 7.3 (5.4) for HIV-uninfected and 8.2 (7.2) for HIVinfected (Table 3). During the hospitalization period, 198 (18\%) died. PTB was diagnosed in 164 of the 896 patients (18\%) who were eventually discharged.

\section{During the follow up period}

77/896 (8.6\%) patients were considered lost-to-follow up (or untraceable). During the 1-year follow up period, 41/896 patients developed confirmed PTB. The overall (all-cause) one-year mortality during follow up was $14 \%$ (123/896 patients). Of these, 19/123 (15\%) had microbiologically proven $\mathrm{TB}$ and $7 / 123$ (6\%) had clinically diagnosed TB (Table 3). 72/896 patients were initially admitted to the general medical ward without a suspicion for PTB (Additional file 2).

\section{Factors associated with active TB and TB-associated mortality post-discharge}

One-year TB incidence and one-year TB-associated mortality were associated with admission in the cohorting bay, HIV infection, CD $4<100$ cells $/ \mathrm{mL}$, and PTB diagnosis during admission (Table 3). Bivariate analysis is shown in the Additional file 3. In multivariable analysis, oneyear TB incidence was independently associated with the number of days that the patient remained hospitalized and proximity to $\mathrm{TB}$ index cases (exposure index) among patients without HIV infection (Table 4). Among HIVinfected patients, one-year TB incidence was independently associated with the number of days that the patient remained hospitalized, but the association with the exposure index was only found among HIV-infected patients who did not have a PTB diagnosis during admission. As expected, history of prior TB infection (particularly resistant TB), a diagnosis of PTB during hospitalization and older age were also associated with TB incidence during follow up (Table 4).

\section{Discussion}

In this study we document the very high rates of nosocomial TB exposure and high levels of one-year TB incidence and mortality after discharge from a tertiary hospital in Sub-Saharan Africa. Our study identified four important groups of patients that may deserve special attention and, perhaps, targeted interventions given their very high rates of nosocomial TB exposure, one-year TB incidence and one-year mortality: a) patients with long hospitalization periods; b) patients cohorted in the TB bay (regardless of their diagnosis of TB); c) patients diagnosed with TB during their hospitalization; and d) HIV-infected 
Table 1 Overview of study features and admission characteristics of 1,094 participants

\begin{tabular}{|c|c|c|c|c|}
\hline & & $\begin{array}{l}\text { Total } \\
\mathrm{n}=1,094\end{array}$ & $\begin{array}{l}\text { Cohorted } \\
n=211\end{array}$ & $\begin{array}{l}\text { General bay } \\
n=883\end{array}$ \\
\hline \multirow[t]{6}{*}{ Age } & $18-29$ years & $298(27.2 \%)$ & $53(25.1 \%)$ & $245(27.7 \%)$ \\
\hline & $30-39$ years & $282(25.8 \%)$ & $56(26.5 \%)$ & $226(25.6 \%)$ \\
\hline & $40-49$ years & $193(17.6 \%)$ & $40(19.0 \%)$ & $153(17.3 \%)$ \\
\hline & $50-59$ years & $114(10.4 \%)$ & $23(10.9 \%)$ & $91(10.3 \%)$ \\
\hline & $60-69$ years & $110(10.1 \%)$ & $25(11.8 \%)$ & $85(9.6 \%)$ \\
\hline & $\geq 70$ years & 97 (8.9\%) & $14(6.6 \%)$ & $83(9.4 \%)$ \\
\hline \multirow[t]{2}{*}{ Sex } & Female & 535 (48.9\%) & $99(46.9 \%)$ & $436(49.4)$ \\
\hline & Male & $559(51.1)$ & $112(53.1 \%)$ & $447(50.6 \%)$ \\
\hline \multirow[t]{3}{*}{ TB History } & No prior TB & $1,018(93.1 \%)$ & $176(83.4 \%)$ & $842(95.4 \%)$ \\
\hline & First line only & $48(4.3 \%)$ & $23(10.9 \%)$ & $25(2.8 \%)$ \\
\hline & Second line & $28(2.6 \%)$ & $12(5.7 \%)$ & $16(1.8 \%)$ \\
\hline \multirow[t]{2}{*}{ HIV } & Negative & 404 (36.9\%) & $9(4.3 \%)$ & $395(44.7 \%)$ \\
\hline & Positive & $690(63.1 \%)$ & $202(5.7 \%)$ & $488(55.3 \%)$ \\
\hline \multirow[t]{6}{*}{ CD4 count } & $<50$ cells $/ \mathrm{mL}$ & $58(8.4 \%)$ & 20 (9.9\%) & $38(7.8 \%)$ \\
\hline & 50 - 99 cells/mL & $100(14.5 \%)$ & $28(13.9 \%)$ & $72(14.8 \%)$ \\
\hline & 100 - 249 cells/mL & $170(24.6 \%)$ & $51(25.2 \%)$ & $119(24.4 \%)$ \\
\hline & 250 - 349 cells/mL & $203(29.4 \%)$ & $53(26.2 \%)$ & $150(30.7 \%)$ \\
\hline & 350 - 499 cells/mL & $73(10.6 \%)$ & $22(10.9 \%)$ & $51(10.5 \%)$ \\
\hline & $\geq 500$ & $86(12.5 \%)$ & $28(13.9 \%)$ & $58(11.9 \%)$ \\
\hline \multicolumn{2}{|c|}{ ART before admission } & $217(31.4 \%)$ & $54(26.7 \%)$ & $163(33.4 \%)$ \\
\hline \multicolumn{2}{|c|}{ ART during admission } & $255(37 \%)$ & $78(38.6 \%)$ & $177(6.2 \%)$ \\
\hline
\end{tabular}

patients with severe immunosuppression. Due to their potentially high risk for development of active TB, education regarding the signs and symptoms of $\mathrm{TB}$ at discharge and close follow up may be recommended. Given the high levels of documented exposure, further preventive interventions such as active follow-up of these patients and/or isoniazid prophylactic therapy may be useful [35-37]. Studies to determine the role of such interventions are needed.
Contrary to what we expected, we found that the total number of days of hospitalization, the total number of days spent at the cohorting bay, the proximity and number of TB index cases that contribute to the cumulative nosocomial $\mathrm{TB}$ exposure and the burden of the index TB case disease (quantified by AFB microscopy) had similar levels of association for incident TB. As expected, however, we found that the relationship between cumulative TB exposure and one-year TB incidence was

Table 2 Radiologic characteristics of inpatients with diagnosis of pulmonary tuberculosis admitted to the medical wards of a tertiary, referral hospital in Sub-Saharan Africa

\begin{tabular}{|c|c|c|c|c|c|}
\hline & & Cohorted & & General & \\
\hline Diagnosis of pneumonia (fever + pulmonary infiltrates of any aetiology) & & 211 & & 132 & \\
\hline \multirow[t]{5}{*}{ Radiological severity } & No $X$ ray available & 9 & $(4 \%)$ & 24 & $(18 \%)$ \\
\hline & Normal & 13 & $(6 \%)$ & 13 & $(10 \%)$ \\
\hline & Mild & 75 & $(36 \%)$ & 28 & $(21 \%)$ \\
\hline & Moderate & 65 & $(31 \%)$ & 33 & $(25 \%)$ \\
\hline & Severe & 49 & $(23 \%)$ & 34 & $(26 \%)$ \\
\hline \multirow[t]{2}{*}{ Cavitary lesions } & Not cavitary & 161 & $(76 \%)$ & 121 & $(92 \%)$ \\
\hline & Cavitary & 50 & $(24 \%)$ & 11 & $(8 \%)$ \\
\hline \multirow[t]{2}{*}{ Radiological extension } & Unilateral & 127 & $(60 \%)$ & 55 & $(42 \%)$ \\
\hline & Bilateral & 84 & (40\%) & 77 & (58\%) \\
\hline
\end{tabular}


Table 3 Inpatient and one-year TB rates and mortality of patients admitted to the medical wards of a tertiary, referral hospital in Sub-Saharan Africa

\begin{tabular}{|c|c|c|c|c|c|c|c|c|c|c|}
\hline Sub-population* & $\begin{array}{c}\text { No. } \\
\text { patients }\end{array}$ & $\begin{array}{l}\text { No. of days } \\
\text { admitted }\end{array}$ & $\begin{array}{l}\text { No. of days in } \\
\text { cohorting }\end{array}$ & $\begin{array}{l}\text { No. of days with an } \\
\text { index case in the } \\
\text { same bay }\end{array}$ & $\begin{array}{l}\text { No. of days } \\
\text { adjacent to } \\
\text { index case }\end{array}$ & $\begin{array}{l}\text { Average TB } \\
\text { exposure } \\
\text { index (SD) }\end{array}$ & $\begin{array}{c}\text { Overall } \\
\text { inpatient } \\
\text { mortality (\%) }\end{array}$ & $\begin{array}{l}\text { TB incidence per } \\
100 \text { persons per } \\
\text { year of follow up }\end{array}$ & $\begin{array}{l}\text { Overall Mortality } \\
\text { per year of } \\
\text { follow-up (\%) }\end{array}$ & $\begin{array}{l}\text { TB-related mortality } \\
\text { per year of follow } \\
\text { up (\%) }\end{array}$ \\
\hline \multicolumn{11}{|l|}{ Place of admission } \\
\hline General bay only & 883 & 5475 & NA & 1035 & 475 & $6.6(5.9)$ & $168(19.0)$ & 16 & 17 & 10 \\
\hline $\begin{array}{l}\text { General bay AND } \\
\text { cohorting bay }\end{array}$ & 80 & 936 & 504 & 1113 & 432 & $18.8(8.6)$ & $2(2.5)$ & 10 & 9 & 6 \\
\hline Cohorting bay only & 131 & 2319 & 1349 & 3211 & 1576 & $33.2(16.1)$ & $8(6.1)$ & 15 & 31 & 6 \\
\hline \multicolumn{11}{|l|}{ HIV status } \\
\hline Positive & 690 & 5728 & 1795 & 3894 & 1787 & 12. (14.1) & $118(17.1)$ & 37 & 43 & 21 \\
\hline Negative & 404 & 3001 & 58 & 1465 & 696 & $8.0(6.3)$ & $60(14.9)$ & 4 & 14 & 1 \\
\hline \multicolumn{11}{|l|}{ CD4 cell count } \\
\hline$<50$ cells $/ \mathrm{mL}$ & 58 & 435 & 198 & 598 & 205 & $11.2(11.5)$ & $4(6.9)$ & 2 & 2 & 4 \\
\hline $50-99$ cells $/ \mathrm{mL}$ & 100 & 880 & 272 & 625 & 283 & $12.8(14.0)$ & $14(14)$ & 6 & 3 & 4 \\
\hline $100-199$ cells $/ \mathrm{mL}$ & 170 & 1343 & 448 & 613 & 434 & $12.0(13.7)$ & $26(15.3)$ & 6 & 4 & 10 \\
\hline $200-349$ cells $/ \mathrm{mL}$ & 203 & 1786 & 440 & 759 & 393 & $11.1(12.8)$ & $35(17.3)$ & 9 & 5 & 9 \\
\hline $350-499$ cells $/ \mathrm{mL}$ & 73 & 664 & 183 & 672 & 209 & $13.2(15.1)$ & $15(20.5)$ & 7 & 5 & 9 \\
\hline$>500$ cells $/ \mathrm{mL}$ & 86 & 619 & 255 & 627 & 263 & $8.0(6.3)$ & $24(28.0)$ & 7 & 2 & 7 \\
\hline \multicolumn{11}{|c|}{$\begin{array}{c}\text { Diagnosis of PTB during } \\
\text { admission }\end{array}$} \\
\hline PTB & 215 & 3139 & 1803 & 2876 & 1978 & $27.1(15.8)$ & $11(5.1)$ & 28 & 17 & 26 \\
\hline No TB & 979 & 5590 & 50 & 2483 & 505 & $6.6(5.9)$ & $167(17.1)$ & 13 & 5 & 31 \\
\hline
\end{tabular}

*The analysis does not include medical patients that died at the Emergency Department, before arriving to the medical wards.

The number of days spent in the same bay with an index case also include the number of days spent with a TB index case adjacent to the patient's bed. 
Table 4 Factors associated with development of pulmonary tuberculosis within $\mathbf{1 2}$ months after discharge from a tertiary hospital in Botswana

\begin{tabular}{|c|c|c|c|c|c|c|c|c|c|}
\hline \multirow[b]{2}{*}{ Variable } & & \multicolumn{4}{|c|}{$\begin{array}{l}\text { Models including participants who were diagnosed with TB during their } \\
\text { inpatient admission, } \mathrm{n}=916\end{array}$} & \multicolumn{4}{|c|}{$\begin{array}{l}\text { Models excluding participants who were diagnosed with TB during } \\
\text { their inpatient admission, } n=713\end{array}$} \\
\hline & & AOR $(95 \% \mathrm{Cl})$ & AOR $(95 \% \mathrm{Cl})$ & AOR $(95 \% \mathrm{Cl})$ & AOR $(95 \% \mathrm{Cl})$ & AOR 95\% C I & AOR $(95 \% \mathrm{Cl})$ & AOR $(95 \% \mathrm{Cl})$ & AOR $(95 \% \mathrm{Cl})$ \\
\hline \multirow[t]{3}{*}{ Age } & 21 - 40 years & Reference & Reference & Reference & Reference & Reference & Reference & Reference & Reference \\
\hline & $41-60$ years & $1.3(0.4-4.9)$ & $0.9(0.3-5.4)$ & $2.5(0.6-10.7)$ & $2.5(0.6-10.8)$ & $1.1(0.2-6.2)$ & $0.9(0.2-5.8)$ & $1.2(0.2-8.4)$ & $1.2(0.2-8.4)$ \\
\hline & $>60$ years & $0.9(0.2-3.5)$ & $1.1(0.3-4.0)$ & $1.3(0.2-7.8)$ & $1.5(0.3-7.6)$ & $2.2(0.4-10.6)$ & $2.1(0.4-10.8)$ & $2.9(0.4-20.5)$ & $2.6(0.5-14.3)$ \\
\hline Sex (male) & & $1.5(0.5-4.2)$ & $1.3(0.5-3.5)$ & $1.7(0.6-5.1)$ & $1.5(0.5-4.4)$ & $0.9(0.2-3.6)$ & $0.9(0.2-3.6)$ & $0.9(0.2-4.2)$ & $0.9(0.2-3.9)$ \\
\hline HIV infection* & & $3.9(0.8-20.5)$ & $2.9(0.6-13.1)$ & $2.7(0.5-15.5)$ & $3.6(0.6-20.0)$ & $2.8(0.4-18.4)$ & $2.7(0.4-17.6)$ & $1.6(0.2-12.6)$ & $1.6(0.2-11.7)$ \\
\hline \multirow[t]{3}{*}{ CD4 cell* count } & CD4 > 350 & Reference & Reference & Reference & Reference & Reference & Reference & Reference & Reference \\
\hline & CD4 $100-350$ & $0.9(0.4-2.1)$ & $0.9(0.3-2.0)$ & $0.8(0.2-2.2)$ & $0.9(0.4-2.1)$ & $0.8(0.4-2.0)$ & $1.2(0.3-8.6)$ & $2.2(0.4-10.6)$ & $3.4(0.4-28.8)$ \\
\hline & $\mathrm{CD} 4<100$ & $3.1(1.3-7.5)$ & $3.6(1.1-6.9)$ & $3.2(1.2-7.2)$ & $2.9(1.2-7.1)$ & $2.8(1.1-6.6)$ & $3.1(1.1-12.6)$ & $3.0(1.1-18.4)$ & $6.5(0.7-61.3)$ \\
\hline \multicolumn{2}{|c|}{ Prior history of TB treatment } & $12.4(3.7-41.1)$ & $11.9(3.8-37.4)$ & $4.6(1.2-17.4)$ & $6.8(2.0-23.6)$ & $10.6(2.6-44.0)$ & $7.8(1.7-36.0)$ & $2.4(0.4-16-4)$ & $3.1(0.5-18.6)$ \\
\hline \multicolumn{2}{|c|}{ Total days admitted to the hospital } & $2.0(1.1-3.6)$ & NA & NA & NA & $1.4(0.6-3.2)$ & NA & NA & NA \\
\hline \multicolumn{2}{|c|}{$\begin{array}{l}\text { Days spent in the same bay with } \\
\text { a TB index case }\end{array}$} & NA & $1.8(1.1-2.9)$ & NA & NA & NA & $1.5(0.4-4.4)$ & NA & NA \\
\hline \multicolumn{2}{|c|}{$\begin{array}{l}\text { Days of adjacent exposure to a TB } \\
\text { index case }\end{array}$} & NA & NA & $4.6(2.2-9.9)$ & NA & NA & NA & $3.4(1.3-8.9)$ & NA \\
\hline \multicolumn{2}{|c|}{ TB exposure index } & NA & NA & NA & $1.9(1.3-2.8)$ & NA & NA & NA & $2.4(1.3-4.2)$ \\
\hline \multicolumn{2}{|c|}{ Inpatient diagnosis of TB } & $2.6(0.8-8.6)$ & $1.6(0.5-5.1)$ & $1.9(0.6-6.0)$ & $1.8(0.6-5.6)$ & & & & \\
\hline
\end{tabular}

*Given collinearity, models including HIV and CD4 cells were developed separately.

Similarly, different models were developed for the variables: a) total days admitted to the hospital; b) days spent in the same bay with a TB index case; c) days of adjacent to a TB index case; and, d) TB exposure score

Total days admitted to the hospital, days spent in the same bay with a TB index case, days of adjacent to a TB index case were modelled as increments by 10 (days). TB exposure index was modelled as an ordinal

variable with increments by 1 point. To calculate the daily exposure index per participant per day, adjacent cases were given twice the weight of non-adjacent ones. For example, if a participant had 2 adjacent TB

cases and one non-adjacent TB patient in his/her bay, the "exposure index" for that day would be calculated as: $2 \times 2+1=5$. 
different by HIV status. However, although the trends and values were different, the probability to develop incident TB after discharge from the hospital increased as the cumulative TB exposure increased, without reaching a plateau. These curves are not comparable to each other but they provide valuable information regarding the effect, type and patterns in which exposure to TB is associated with TB incidence (data not shown).

Not unexpectedly, we document significant differences in $\mathrm{TB}$ incidence by cumulative exposure to $\mathrm{TB}$ patients cohorted on the TB bay. Although the lack of control group (hospitals that do not cohort TB patients) does not allows us to draw conclusions about the efficacy of this strategy in decreasing the overall net nosocomial TB exposure, it does highlights the nature of the resulting exposure and identify potential future targets for further intervention. Point-of-care diagnostic tools for TB, such as the recently developed GeneXpert MTB/RIF are likely to contribute significantly to the accurate triage of patients on admission $[15,16,38,39]$. Such triage will likely decrease TB exposure if other infection control measures are also maximized. However, given the high prevalence of other factors leading to nosocomial TB exposure in busy hospitals where TB and HIV infection are highly prevalent, the impact of such technologies in reducing nosocomial TB transmission remains to be determined.

Our study has several limitations. First, in spite of all our attempts to quantify the variables that could potentially lead to nosocomial TB transmission, there are no gold-standards to quantify the degree of exposure. Our surrogates (distance between patients and position in the bay), can only give us a rough idea of the magnitude of the level of exposure and risk for TB acquisition at the hospital. Furthermore, the scale used to compare the degree of exposure between the groups may fail to include other factors that are likely to influence the risk for nosocomial TB transmission such as host immunosuppression and immune-related factors, virulence of the pathogen, infectiousness of the index case and environmental factors among others. We believe that the development of more accurate measures of exposure will significantly improve the study of TB transmission in the future and research in that area needs to be prioritized. Nevertheless, in spite of its limitations, our attempt to measure the intensity of exposure was useful to demonstrate a significant difference in the exposure of patients admitted to the general ward when compared to the patients admitted to the TB cohorting bay. Second, our study was conducted over a 3month period and 1 years of follow-up, providing only a snapshot of the situation. The lack of active case finding through sputum induction and culture of patients with cough, likely led to an underestimation of the number of active TB cases admitted to the wards during that time period. Similarly, the lack of a prospective follow up of the patients admitted to the wards during the study period does not allow us to estimate the impact of such exposure on transmission of disease. Our score would need to be correlated with the rate of development of TB infection among a closely-monitored cohort of patients in order to make it clinically meaningful. Fully aware of these limitations, we do not recommend the use of our scoring system used in our study to be used for any clinical or infection control decisions. As mentioned, the main objective of the scoring system was to allow the comparison between different settings in the medical ward.

In spite of these limitations, we believe the results of our study accurately depict the situation at a major hospital in a high HIV and TB prevalence area under real-world implementation conditions. Given that the environmental conditions, patient population and hospital procedures are similar to the ones present at a large number of highvolume large referral centres in areas with high prevalence of HIV and TB infection, we believe our results are also generalizable to similar settings. Our study highlights some of the difficulties for the implementation of effective infection control measures aims to reduce TB exposure among inpatients in low-resource settings. Until the best way to reduce such exposure is determined, simple but effective infection control measures that may decrease TB exposure must be prioritized. Among others, outpatient management of TB patients should be encouraged when possible. Rapid diagnosis, initiation of treatment and discharge should be implemented for patients admitted to the hospital. Appropriate cross-ventilation, as well as the use of surgical masks and cough hygiene practices on patients known to have TB should also be performed. Studies to determine the best way to triage patients being admitted to the hospital and minimize the TB exposure of patients at highest risk for nosocomial TB acquisition are in high need.

\section{Conclusion}

The number of days spent in medical wards in Botswana is strongly associated with development of TB within the following 12 months after discharge. TB-related mortality is very high among these patients. TB incidence and TB-associated mortality during follow up are associated with the overall time spent as an inpatient, the time spent at the cohorting bay, the time spent contiguously to a TB index case.

\section{Additional files}

Additional file 1: Figure S1. Decision algorithm for patient triage to a tubeculosis cohorting bay.

Additional file 2: Shows the distribution of patients according to their suspicion for tuberculosis on admission, allocation on the ward and ultimate diagnosis of pulmonary tuberculosis. 
Additional file 3: Table S1. Bivariate analysis of the main co-factors potentially associated with one-year incident tuberculosis and one-year mortality.

\section{Competing interests}

The authors declare no competing interests.

\section{Authors' contributions}

Dr NZ had full access to all the data in the study and take responsibility for the integrity of the data and the accuracy of the data analysis. Study concept and design: CM, NZ, NM, AP. Acquisition of data: CM, NZ, NM, RC, RN, NM, AP. Analysis and interpretation of data: CM, NZ, RN, KJ, RC, SS. Drafting of manuscript: NZ, NM. Critical revision of the manuscript for important intellectual content: CM, NZ, RN, SS, JK, RC. Statistical analysis: CM, NZ, NM, AP. Obtaining funding: NZ. Administrative, technical, or material support: CM, AP, NM. Study supervision: NZ, RC. All authors read and approved the final manuscript.

\section{Financial support}

This work was supported by NIH grant P30Al45008 (Penn Center for AIDS Research) and Health Services and Human Research grant 1U2GPS001949 (President's Emergency Plan for AIDS Relief). The funders had no role in study design, data collection and analysis, decision to publish, or preparation of the manuscript.

\section{Author details}

${ }^{1}$ Division of Infectious Disease, University of Pennsylvania, Philadelphia, Pennsylvania, USA. ${ }^{2}$ University of Botswana Medical School, University of Botswana, Gaborone, Botswana. 'Botswana-UPenn Partnership, Gaborone, Botswana. ${ }^{4}$ Division of Infectious Diseases, University of Melbourne, Melbourne, Australia. ${ }^{5}$ School of Medicine, University of California, Los Angeles, USA. ${ }^{6}$ Botswana National TB Program, Gaborone, Botswana. ${ }^{7}$ Division of Pulmonary and Critical Care Medicine, University of Pennsylvania, Philadelphia, Pennsylvania, USA.

\section{Received: 17 February 2014 Accepted: 11 July 2014}

Published: 22 July 2014

\section{References}

1. World Health Organization: TB / HIV fact sheet 2009. In Geneva: World Health Organization; 2009. Available at http://www.who.int/tb/challenges/ hiv/factsheet_hivtb_2009.pdf

2. WHO's Multidrug and Extensively Drug-Resistant Tuberculosis: 2010 Global Report on Surveillance and Response. In Geneva: World Health Organization; 2010

3. Bock NN, Jensen PA, Miller B, Nardell E: Tuberculosis infection control in resource-limited settings in the era of expanding HIV care and treatment. J Infect Dis 2007, 196(Suppl 1):S108-S113.

4. Reid MJ, Saito S, Nash D, Scardigli A, Casalini C, Howard AA: Implementation of tuberculosis infection control measures at HIV care and treatment sites in sub-Saharan Africa. Int J Tuberc Lung Dis 2012, 16(12):1605-1612.

5. Basu S, Andrews JR, Poolman EM, Gandhi NR, Shah NS, Moll A, Moodley P, Galvani AP, Friedland GH: Prevention of nosocomial transmission of extensively drug-resistant tuberculosis in rural South African district hospitals: an epidemiological modelling study. Lancet 2007, 370(9597):1500-1507.

6. Di Perri G, Cruciani M, Danzi MC, Luzzati R, De Checchi G, Malena M, Pizzighella S, Mazzi R, Solbiati M, Concia E: Nosocomial epidemic of active tuberculosis among HIV-infected patients. Lancet 1989, 2(8678-8679):1502-4.

7. Frieden TR, Woodley CL, Crawford JT, Lew D, Dooley SM: The molecular epidemiology of tuberculosis in New York City: the importance of nosocomial transmission and laboratory error. Tuber Lung Dis 1996, 77(5):407-413.

8. van der Zanden AG, Bosje T, Heilmann FG, van Soolingen D: Nosocomial transmission of tuberculosis to a nurse demonstrated by means of spoligotyping of a formalin-fixed bronchial biopsy. Neth J Med 2001, 59(3):152-157.
9. Wilkinson D, Crump J, Pillay M, Sturm AW: Nosocomial transmission of tuberculosis in Africa documented by restriction fragment length polymorphism. Trans R Soc Trop Med Hyg 1997, 91(3):318.

10. World Health Organization: WHO Policy on TB Infection Control in Health-Care Facilities. Geneva: Congregate Settings and Households; 2009.

11. Farley JE, Tudor C, Mphahlele M, Franz K, Perrin NA, Dorman S, Van der Walt $\mathrm{M}$ : A national infection control evaluation of drug-resistant tuberculosis hospitals in South Africa. Int J Tuberc Lung Dis 2012, 16(1):82-89.

12. Sokolove PE, Lee BS, Krawczyk JA, Banos PT, Gregson AL, Boyce DM, Lewis RJ: Implementation of an emergency department triage procedure for the detection and isolation of patients with active pulmonary tuberculosis. Ann Emerg Med 2000, 35(4):327-336.

13. Theron G, Peter J, van Zyl-Smit R, Mishra H, Streicher E, Murray S, Dawson R, Whitelaw A, Hoelscher M, Sharma S, Pai M, Warren R, Dheda K: Evaluation of the Xpert MTB/RIF assay for the diagnosis of pulmonary tuberculosis in a high HIV prevalence setting. Am J Respir Crit Care Med 2011, 184(1):132-140.

14. Marlowe EM, Novak-Weekley SM, Cumpio J, Sharp SE, Momeny MA, Babst A, Carlson JS, Kawamura M, Pandori M: Evaluation of the Cepheid Xpert MTB/RIF assay for direct detection of Mycobacterium tuberculosis complex in respiratory specimens. J Clin Microbiol 2011, 49(4):1621-1623.

15. Boehme CC, Nicol MP, Nabeta P, Michael JS, Gotuzzo E, Tahirli R, Gler MT, Blakemore R, Worodria W, Gray C, Huang L, Caceres T, Mehdiyev R, Raymond L, Whitelaw A, Sagadevan K, Alexander H, Albert H, Cobelens F, Cox H, Alland D, Perkins MD: Feasibility, diagnostic accuracy, and effectiveness of decentralised use of the Xpert MTB/RIF test for diagnosis of tuberculosis and multidrug resistance: a multicentre implementation study. Lancet 2011, 377(9776):1495-1505.

16. World Health Organization: World Health Organization Rapid implementation of the Xpert MTB/RIF diagnostic test. In Geneva, Switzerland: WHO; 2011. WHO/HTM/TB/2011.2.

17. Sibanda T, Tedla Z, Nyirenda S, Agizew T, Marape M, Miranda AG, Reuter H, Johnson JL, Samandari T: Anti-tuberculosis treatment outcomes in HIV-infected adults exposed to isoniazid preventive therapy in Botswana. Int J Tuberc Lung Dis 2013, 17(2):178-185.

18. Schwartz AB, Tamuhla N, Steenhoff AP, Nkakana K, Letlhogile R, Chadborn TR, Kestler M, Zetola NM, Ravimohan S, Bisson GP: Outcomes in HIV-infected adults with tuberculosis at clinics with and without co-located HIV clinics in Botswana. Int J Tuberc Lung Dis 2013, 17(10):1298-1303.

19. Hafkin J, Modongo C, Newcomb C, Lowenthal E, MacGregor RR, Steenhoff AP, Friedman H, Bisson GP: Impact of the human immunodeficiency virus on early multidrug-resistant tuberculosis treatment outcomes in Botswana. Int J Tuberc Lung Dis 2013, 17(3):348-353.

20. Kurbatova EV, Taylor A, Gammino VM, Bayona J, Becerra M, Danilovitz M, Falzon D, Gelmanova I, Keshavjee S, Leimane V, Mitnick CD, Quelapio MI, Riekstina V, Viiklepp P, Zignol M, Cegielski JP: Predictors of poor outcomes among patients treated for multidrug-resistant tuberculosis at DOTS-plus projects. Tuberculosis (Edinb) 2012, 92(2):397-403.

21. Jacobson KR, Tierney DB, Jeon CY, Mitnick CD, Murray MB: Treatment outcomes among patients with extensively drug-resistant tuberculosis: systematic review and meta-analysis. Clin Infect Dis 2010, 51(1):6-14.

22. Orenstein EW, Basu S, Shah NS, Andrews JR, Friedland GH, Moll AP, Gandhi NR, Galvani AP: Treatment outcomes among patients with multidrug-resistant tuberculosis: systematic review and meta-analysis. Lancet Infect Dis 2009, 9(3):153-161.

23. Kwon YS, Kim YH, Suh GY, Chung MP, Kim H, Kwon OJ, Choi YS, Kim K, Kim J Shim YM, Koh WJ: Treatment outcomes for HIV-uninfected patients with multidrug-resistant and extensively drug-resistant tuberculosis. Clin Infect Dis 2008, 47(4):496-502.

24. Addis Alene K, Nega A, Wasie Taye B: Incidence and predictors of tuberculosis among adult people living with human immunodeficiency virus at the University of Gondar Referral Hospital. Northwest Ethiopia. BMC Infect Dis 2013, 13:292.

25. Aguiar F, Vieira MA, Staviack A, Buarque C, Marsico A, Fonseca L, Chaisson R, Kristski A, Werneck G, Mello F: Prevalence of anti-tuberculosis drug resistance in an HIV/AIDS reference hospital in Rio de Janeiro, Brazil. Int J Tuberc Lung Dis 2009, 13(1):54-61.

26. Gandhi NR, Weissman D, Moodley P, Ramathal M, Elson I, Kreiswirth BN, Mathema B, Shashkina E, Rothenberg R, Moll AP, Friedland G, Sturm AW, 
Shah NS: Nosocomial transmission of extensively drug-resistant tuberculosis in a rural hospital in South Africa. J Infect Dis 2013, 207(1):9-17.

27. Garedew L, Mihret A, Mamo G, Abebe T, Firdessa R, Bekele Y, Ameni G Strain diversity of mycobacteria isolated from pulmonary tuberculosis patients at Debre Birhan Hospital, Ethiopia. Int J Tuberc Lung Dis 2013, 17(8):1076-1081

28. Goncalves MJ, Ferreira AA: Factors associated with length of hospital stay among HIV positive and HIV negative patients with tuberculosis in Brazil. PloS One 2013, 8(4):e60487.

29. Khanna P, Nikolayevskyy V, Warburton F, Dobson E, Drobniewski F: Rate of latent tuberculosis infection detected by occupational health screening of nurses new to a london teaching hospital. Infect Control Hosp Epidemiol 2009, 30(6):581-584.

30. Liu CH, Li L, Chen Z, Wang Q, Hu YL, Zhu B, Woo PC: Characteristics and treatment outcomes of patients with MDR and XDR tuberculosis in a TB referral hospital in Beijing: a 13-year experience. PLoS One 2011, 6(4):e19399.

31. Van Duc L, Vree M, Cobelens FG, Phuc LT, Sy DN: High tuberculosis prevalence in a psychiatric hospital in Vietnam. Int J Tuberc Lung Dis 2008, 12(6):686-688

32. Botswana Ministry of Health: Botswana National TB Program Manual. In 6th edition. Gaborone; 2007.

33. Botswana National Tuberculosis Programme Report. In 2009.

34. World Health Organization: Treatment of tuberculosis: guidelines for national programmes. In 3rd edition. Geneva: World Health Organization; 2004. WHO/CDS/TB/2003.313

35. Samandari T, Agizew TB, Nyirenda S, Tedla Z, Sibanda T, Shang N, Mosimaneotsile B, Motsamai Ol, Bozeman L, Davis MK, Talbot EA, Moeti TL, Moffat HJ, Kilmarx PH, Castro KG, Wells CD: 6-month versus 36-month isoniazid preventive treatment for tuberculosis in adults with HIV infection in Botswana: a randomised, double-blind, placebo-controlled trial. Lancet 2011, 377(9777):1588-1598.

36. Date AA, Vitoria M, Granich R, Banda M, Fox MY, Gilks C: Implementation of co-trimoxazole prophylaxis and isoniazid preventive therapy for people living with HIV. Bull World Health Organ 2010, 88(4):253-259.

37. Tedla Z, Nyirenda S, Peeler C, Agizew T, Sibanda T, Motsamai O, Vernon A, Wells CD, Samandari T: Isoniazid-associated hepatitis and antiretroviral drugs during tuberculosis prophylaxis in hiv-infected adults in Botswana. Am J Respir Crit Care Med 2010, 182(2):278-285.

38. Van Rie A, Page-Shipp L, Scott L, Sanne I, Stevens W: Xpert((R)) MTB/RIF for point-of-care diagnosis of TB in high-HIV burden, resource-limited countries: hype or hope? Expert Rev Mol Diagn 2010, 10(7):937-946.

39. Boehme C: Feasibility and impact of using Xpert MTB/RIF: results from demonstration studies. In Geneva, Switzerland: Foundation for Innovative New Diagnostics; 2010 [Accessed July 2013].

doi:10.1186/1471-2334-14-409

Cite this article as: Zetola et al:: Longer hospital stay is associated with higher rates of tuberculosis-related morbidity and mortality within 12 months after discharge in a referral hospital in Sub-Saharan Africa. BMC Infectious Diseases 2014 14:409.

\section{Submit your next manuscript to BioMed Central and take full advantage of:}

- Convenient online submission

- Thorough peer review

- No space constraints or color figure charges

- Immediate publication on acceptance

- Inclusion in PubMed, CAS, Scopus and Google Scholar

- Research which is freely available for redistribution 